\title{
Information // Message
}

\author{
Lisa Borgenheimer \\ Free University of Bolzano, Faculty of Art and Design, Universitätsplatz 1, Italy \\ info@lisaborgenheimer.com
}

\begin{abstract}
Both elements, the information and the message, are present in information graphics. The information is the translation of the data into visual structures. The message narrates the story the author intended to tell and to point out. Creating meaningful messages within information graphics can lead to more effectiveness in the knowledge transfer, but can also be used to generate propaganda. Therefore the method of visual storytelling can be used to convey informative messages within various settings and contexts. The process is the visual translation of contents into informative and narrative graphics, which can orientate on factual, statistical correctness or on telling emotional stories. Due to that, the information and message are adjusted to the users' needs and interests. In the end, using target-oriented visual storytelling has a higher impact on the knowledge transfer and the users' attention.

Reflecting on existing graphics and visual forms, the following text focuses on the various intentions of telling stories.
\end{abstract}

Keywords: Methodology, Visual Narrative, Storytelling, Semantics

\section{Introduction}

The research started as a master student at the University of Applied Sciences in Augsburg, where I developed a method for analogue and interactive information design as my master thesis. After that, I was mainly interested in the methodology of visual storytelling for information graphics and information design. Therefore I started working between practice and theory. During my time at the Free University of Bolzano, I'm doing research on the discrepancy between the statistical data and the ready-to-sell information graphics, by working on different projects and topics.

The content of information//message is a basic thought of my practice-oriented theory, which is also affecting my outcoming artefacts done with information design or information graphics. In the following text, I would like to point out this theory and relate it to my current practical research on "Communication for participatory democracy - Participatory Budgeting in Mals/Malles (Alta Val Venosta, Italy)". This ongoing project (June 2016 - June 2018) was funded by the Free University of Bolzano and is a collaboration with the municipality of Mals/Malles, POLITis and the Faculty for Education (unibz). 


\section{Information // Message}

The information and the message are always part of information graphics. Therefore the information is based on the dataset and the statistical translation. Whereas the message is the composed result of the content-related semantic elements, which generates particular metaphors.

On the basis of the own constructive perception, the information transfer has interfered and the possible metaphors are the consequences of intended or unintended messages, developed by the author or graphic designer.

The main difference between the information and the message is the method of visual translation. The focus on the statistical correctness or the composition of an emotional narrative is shifting the graphic to an information or message-based visualization. Therefore an information-orientated graphic is displaying the statistical aspect in a factual way. Instead, the message-orientated graphic is showing the emotional narratives.

\subsection{People and Data}

An information graphic is constantly related to a specific target group. Due to that, there is a difference in the complexity, the speaking voice and of course the overall visual appearance.

Creating a graphic means to perceive the (previous) knowledge of the topic, the interests and the possible behaviour of individuals and groups. It is necessary to consider the potential interpretation of the visualisation and the upcoming effect or impact, which can come instantly or later on.

The graphic designer/author/etc. needs to find the important information in the dataset and transforms it into a meaningful message, which can be understood by the related target group. This selected data illustrates an issue and contains meaningful and relevant information, which can be indicated in a message. In the end, this message is directing and narrating the specific issue.

\subsection{Design for Democracy}

As part of my PhD at the Bauhaus-University Weimar (DE) and my research at the Free University of Bolzano (IT), I am concentrating on target-group generated content with information-oriented and also message-oriented information design and graphics. My intention is to find the link between the proposition of the information // message together with a practical and tangible example.

My research project on participatory budgeting, together with the community in Mals/Malles, holds a strong connection to the citizens. Consequently, it was fundamental to create a strategy/method for communicating complex topics for people at the age of $14-99$, with different perception and knowledge of political issues. 
The first step was to determine the information and message based visualisations on the subject of participatory budgeting. Therefore, I analyzed the main issues of the process and the possible interests of the target group.

For sure, the discussion of available money is the most attractive information to mainly concentrate. But there are also other elements of the process, which need to be recognized: e.g. handing-in ideas, the decision-making and also the democratic election of projects, which is showing the acceptance of project-ideas within the community. However, the implicit message of the whole procedure carries the common and individual identity of the involved people and the potential changes within the local area.

\subsection{Communication for Participatory Democracy}

Using the information // message within this project, created a division between factual and emotional storytelling and the outgoing visual knowledge transfer. Therefore the different topics had a higher tendency to focus on the factual information or on emotional messages.

Talking about costs, investments, process planning needed a more reliable and legitimated translation of the datasets to underline the seriousness of the whole procedure. Therefore the visualizations need to show the facts with appropriate graphics, like bar/column charts, line charts, etc. to orientate on the informationtransfer.

Compared to the emotional part, the graphics have higher illustrative characteristics and physical/materialistic references to make the topic more tangible for the citizens. The graphics show the situation of taking part in the political procedure and how to behave in this situation. Therefore all visualizations are more related to the message and the metaphors, which are generating the stories.

\section{Conclusion}

Facts and narratives are connecting different people and identities. Concentrating on the method of information // message, to get the data understood by the citizens with different ages and familiarity, can help to facilitate the general knowledge transferring insights into various visual formats and are enabling to perceive the topic from different perspectives. The method opens more possibilities in style, graphic design, editorial design, etc. and makes the author think and not "just translate" the data into information graphics. Instead, the designer needs to consider the target groups' intentions, surroundings, influences and impacts by using the visual translation, which turns the data into concrete shapes and forms information-based or message-based. 

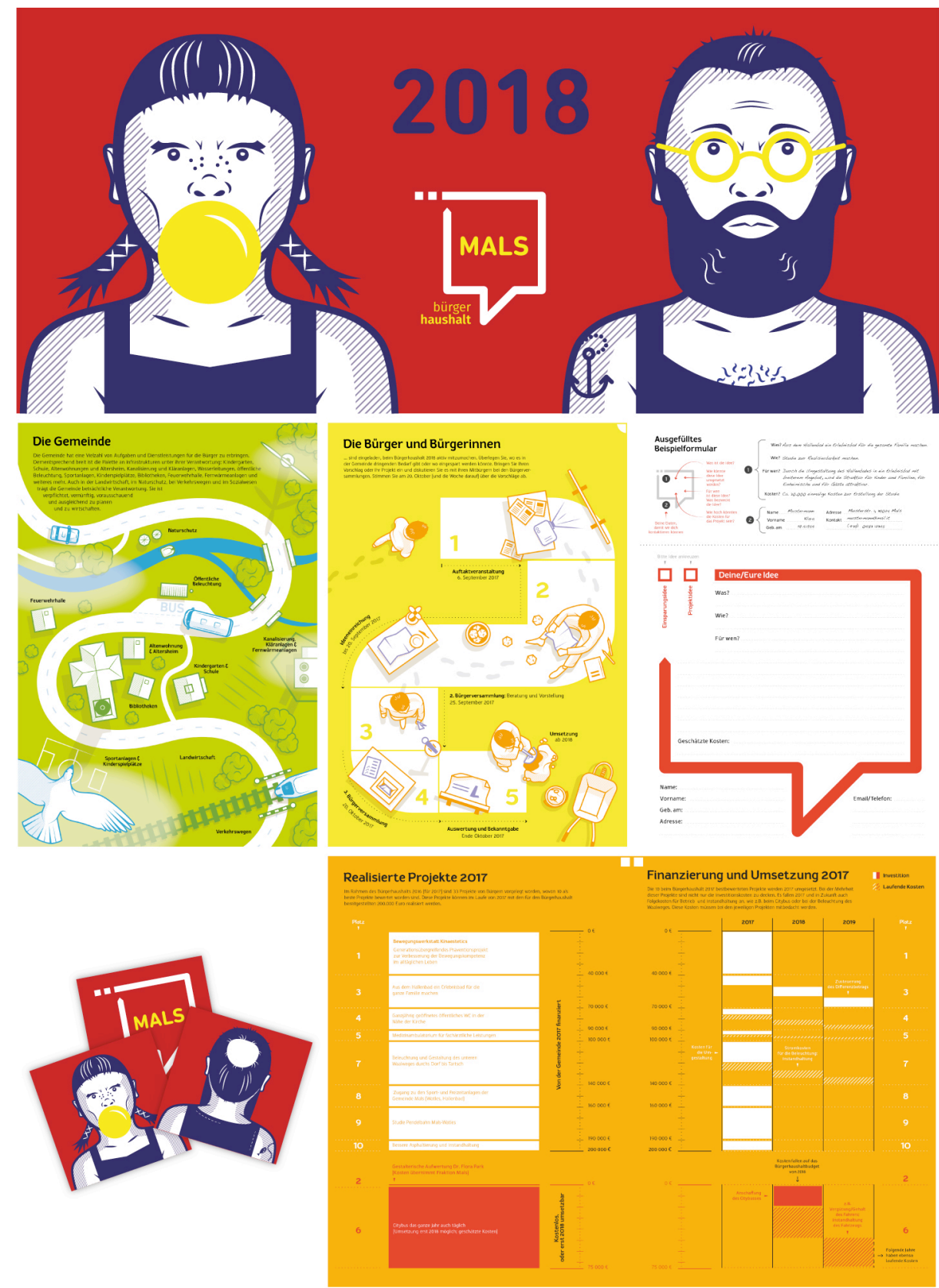

Fig. 1. Borgenheimer, L., Benedikter T., Bernhard A. (2017). Bürgerhaushalt 2017. Marktgemeinde Malles. Italy. Gemeinde Mals/Malles. 


\section{References}

\section{Books}

Benedikter, T. (2013), Die Gemeindefinanzen mitbestimmen - Der Bürgerhaushalt.

Bozen, Italien: POLITiS Bozen

Pörksen, U. (1997), Weltmarkt der Bilder. Stuttgart, Deutschland: Klett-Cotta

Yau, N. (2013), Data Points: Visualization That Means Something. Indianapolis, USA: John Wiley \& Sons Inc.

\section{Magazine}

Borgenheimer, L., Benedikter, T., Bernhard, A. (2016), Bürgerhaushalt 2017. Marktgemeinde Mals/Malles, Italy: Gemeinde Mals

Borgenheimer, L., Benedikter, T., Bernhard, A. (2017), Bürgerhaushalt 2018. Marktgemeinde Mals/Malles, Italy: Gemeinde Mals

\section{Website}

Yau, N. (2017), One Dataset, Visualized in 25 Ways, Retrieved from:

http://flowingdata.com/2017/01/24/one-dataset-visualized-25-ways/ 